\title{
The Relationship between Metal Exposure and Chronic Obstructive Pulmonary Disease in the General US Population: NHANES 2015-2016
}

\author{
Qiaoyuan Fei ${ }^{1,+}$, Xueqiong Weng ${ }^{1,+}$, Kun Liu ${ }^{1,+}$, Shan Liu ${ }^{1}$, Jingmin Chen ${ }^{1}$, Xinrong Guo ${ }^{1}$ and Chunxia Jing ${ }^{1,2, *}$ \\ 1 Department of Public Health and Preventive Medicine, School of Medicine, Jinan University, \\ No.601 6 Huangpu Ave West, Guangzhou 510632, China; qy824559259@163.com (Q.F.); \\ wengxueqiong111@gmail.com (X.W.); liukungyyf@163.com (K.L.); lshliushan@163.com (S.L.); \\ canotwwwwait@stu2019.jnu.edu.cn (J.C.); abbyla@foxmail.com (X.G.) \\ 2 Guangdong Key Laboratory of Environmental Exposure and Health, Jinan University, \\ Guangzhou 510632, China \\ * Correspondence: jcxphd@gmail.com; Tel.: +86-20-8522-0258 \\ + These authors contributed equally to this work.
}

check for updates

Citation: Fei, Q.; Weng, X.; Liu, K.; Liu, S.; Chen, J.; Guo, X.; Jing, C. The Relationship between Metal Exposure and Chronic Obstructive Pulmonary Disease in the General US Population: NHANES 2015-2016. Int. J. Environ. Res. Public Health 2022, 19, 2085. https://doi.org/10.3390/ ijerph19042085

Academic Editor: Luke Knibbs

Received: 7 January 2022

Accepted: 10 February 2022

Published: 13 February 2022

Publisher's Note: MDPI stays neutral with regard to jurisdictional claims in published maps and institutional affiliations.

Copyright: (C) 2022 by the authors. Licensee MDPI, Basel, Switzerland. This article is an open access article distributed under the terms and conditions of the Creative Commons Attribution (CC BY) license (https:// creativecommons.org/licenses/by/ $4.0 /)$.

\begin{abstract}
The effects of metal on pulmonary function are inconsistent, and abnormal distribution of metals can decrease lung function. However, the effects of metals exposure on chronic obstructive pulmonary disease (COPD) are still unclear. This study aims to explore the relationship between metal exposure and COPD risk. Cross-sectional data from the National Health and Nutrition Survey (NHANES) 2015-2016 was analyzed. Inductively coupled plasma dynamic reaction cell mass spectrometry (ICP-DRC-MS) was used to measure the metals concentration in the blood. The multiple linear regression and restricted cubic spline (RCS) were used to analyze the relationship between metals exposure and COPD risk. In this study, 1399 participants were included, of which 107 participants were diagnosed with COPD using self-reported chronic bronchitis, emphysema, and COPD. The second and third tertiles of copper increased the COPD risk by 1.98 -fold (95\% CI: 1.08-3.62) and 2.43-fold (95\% CI: 1.32-4.48) compared with the first tertile, using $p=0.005$ for the trend after adjusting for the covariates. RCS showed a positive linear correlation between copper and COPD risk ( $p=0.006$ for overall association) in all participants. When stratified by sex, the multi-factor analysis showed that the third tertile of copper increased male's COPD risk by 3.42-fold (95\% CI: 1.52-7.76), with $p=0.003$ for the trend, and RCS also showed a positive linear correlation ( $p=0.013$ for overall association). Although RCS showed that selenium can reduce the COPD risk ( $p=0.008$ for overall association) in males, an association between selenium and COPD was not observed $(p>0.05)$. Our findings suggest that a high concentration of copper may increase COPD risk in males in the general US population, and more research is needed to explore its possible mechanism of action.
\end{abstract}

Keywords: metals; trace minerals; COPD; RCS; copper

\section{Introduction}

Chronic obstructive pulmonary disease (COPD) is a disease characterized by persistent airflow limitation caused by large amounts of exposure to toxic particles and gases. It includes chronic bronchial and emphysema [1]. The most common symptoms of COPD are dyspnea, cough, and sputum production [2]. According to statistics from the World Health Organization (WHO), there are currently about 600 million people suffering from COPD in the world, and an average of about 2.7 million people die from COPD every year [3]. Due to the high prevalence, morbidity, and mortality of COPD, it has brought a great burden of disease to the world, it has always been one of our main public health issues [4]. COPD ranked 11th among the top 15 major diseases that caused the loss of 
disability-adjusted healthy life years in 1990, and by 2019, COPD rose to 6th. Additionally, $66 \%$ of the global burden of COPD and lung cancer comes from low- and middle-income countries [5]. Smoking, indoor air pollution (such as biofuels used for cooking and heating), outdoor air pollution, occupational dust, and chemicals are the main risk factors for COPD, among which smoking is the most important factor [6-8]. Therefore, the first measure to prevent and treat COPD is to quit smoking. In addition, vaccinations and drugs can also be used to prevent and treat COPD [2].

Metals may have different effects on pulmonary function. Copper, zinc, and selenium are essential trace elements for the human body. Copper in tap water was positively related to levels of both FVC and FEV1 among never smokers [9]. Xiao, Zhou et al. reported that copper can reduce the forced expiratory volume in $1 \mathrm{~s}$ [10]. Cadmium can enter the human body with tobacco drugs and can accumulate in the body, especially in the lungs [11,12], and the accumulation of cadmium can cause lung inflammation and a decline in lung function [13-15]. Zinc has an antagonistic effect on the toxicity of cadmium and copper [13,16]. A lack of zinc may lead to impaired immune function and tumor development [17-19]. An increased prevalence of obstructive lung disorder was observed among individuals with low zinc intake regardless of smoking status, and the adjusted odds of lung disorder are approximately 1.9 times greater for subjects in the lowest zinc-intake tertile than those in the highest tertile (odds ratio $=1.89,95 \%$ confidence interval $=1.22-2.93$ ) [20]. Selenium is related to the cellular antioxidant defense mechanism. Oxidative stress and chronic inflammation are important features in the pathogenesis of COPD [21]. However, the relationship between selenium and COPD is unclear. Studies have shown that the accumulation of manganese reduces the expression of cystic fibrosis transmembrane conductance regulator (CFTR), which is a chloride channel located in airway epithelial cells. CFTR plays an important role in maintaining the dynamic balance of airway surface fluid (ASL) volume and the physiological function of the lungs. If the expression decreases or the function is impaired, the lungs cause mucus accumulation, reduced bacterial clearance, and chronic infection and inflammation [22]. A study in NHANES 2007-2010 found a dose-dependent relationship between blood lead concentration and the risk of COPD [23].

Since the associations between metal exposure and trace minerals, and COPD remain unclear, and nothing is known about their dose-response relationship, we used the data from NHANES (2015-2016) to explore the relationship between metal and trace minerals, and COPD.

\section{Materials and Methods}

\subsection{Study Population}

The National Health and Nutrition Examination Survey (NHANES) is a cross-sectional survey based on the whole population of the United States. The study protocol was approved by the NCHS Research Ethics Review Board (Continuation of Protocol \#201117), and all participants provided written informed consent. It combines questionnaire surveys and physical examinations to collect information about the health and nutrition of the American family population, including demographics, diet-related issues, physical examinations, laboratory examinations, and more [11].

The data from NHANES 2015-2016 was analyzed, and the 9971 participants were screened. We merged the databases based on the unique identity of the survey subjects. After merging the databases, we excluded 8572 who had missing data in physical examination, medical conditions, drinking, smoking, second-hand smoke exposure, serum cotinine, hypertension, diabetes, and blood metal measurements. Finally, 1399 survey subjects were included in the study, including 694 males and 705 females (Figure 1). 


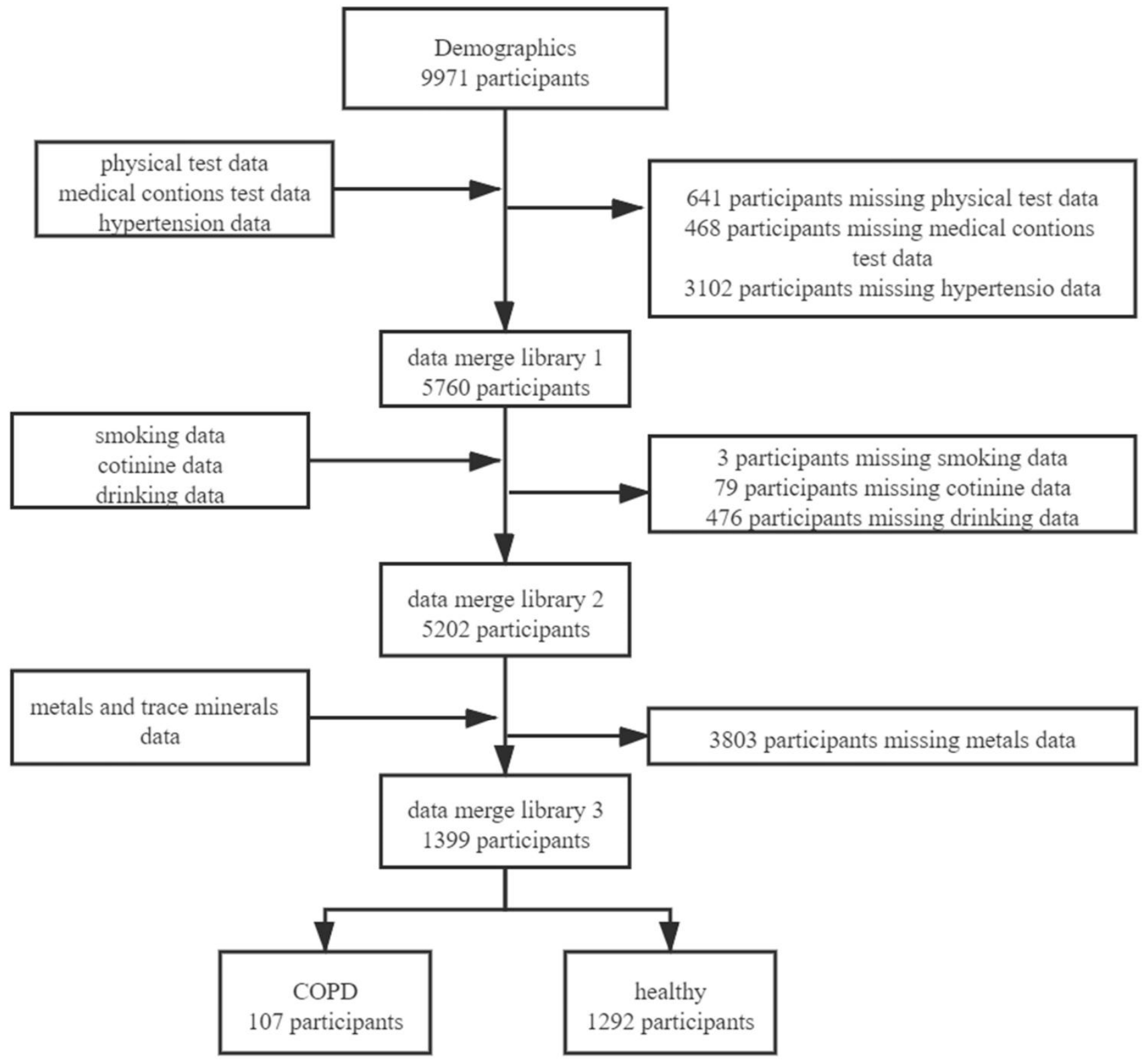

Figure 1. Flowchart for the inclusion of study participants.

\subsection{Metal and Trace Mineral Measurements}

The processed blood were stored under $-20{ }^{\circ} \mathrm{C}$ conditions and sent to the laboratory for analysis. The levels of metals were measured using inductively coupled plasma dynamic reaction cell mass spectrometry (ICP-DRC-MS) by the Centers for Disease Control and Prevention in the US [24-26].

\section{3. $C O P D$}

Current chronic bronchitis was defined by positive answers to the questions (1) "Has a doctor or other health professional ever told you that you have chronic bronchitis?" and (2) "Do you still have chronic bronchitis?" Emphysema was defined by positive answers to the questions: "Has a doctor or other health professional ever told you that you have emphysema?" COPD was defined by positive answers to the questions: "Has a doctor or other health professional ever told you that you have COPD?" [1]. 


\subsection{Smoking and Secondhand Smoke Exposure}

Smokers were divided into three groups: non-smokers, current smokers, and former smokers. Non-smokers were defined as smoking less than 100 cigarettes in their lifetime. Current smokers were defined as smoking more than 100 cigarettes in their lifetime and were still smoking. Former smokers were defined as smoking more than 100 cigarettes in their lifetime but not smoking now [20,27].

Participants who had been to jobs, bars, restaurants, other homes, and other indoor places and who had smoked cigarettes in these places were included in the secondhand smoke exposure group.

\subsection{Drinking}

Participants were divided into drinking groups and non-drinking groups according to whether they had drunk more than 12 alcoholic drinks in their lifetime [28].

\subsection{Covariates}

We included the covariates based on previous studies [3,29], which might be related to COPD or the concentration of metal. We collected basic information about participants through questionnaires, including gender; age; race (Mexican American, other Hispanic, non-Hispanic white, non-Hispanic black, and other race); education (less than 9th grade, 9-11 grade, high school graduate, some college/AA degree, and college graduate); the ratio of family income to poverty and BMI $(<18.5,18.5-25,25-30, \geq 30)$; and hypertension and diabetes, which might be related to COPD or the concentration of metal [3,29].

\subsection{Statistical Analysis}

All analyses were performed with Stata version 15.0 (StataCorp LP, College Station, Texas, USA) and R software version 4.1.0 (R Foundation for Statistical Computing, Vienna, Austria). RCS was implemented with the R package "rms" (version 6.1-1) (Frank Harrell, Nashville, Tennessee, USA). The continuous variables were represented by mean \pm SD, non-normally distributed continuous variables were represented by the interquartile range (IQR), and categorical variables were represented by cases (n) and percentage (\%). The Chi-square test was used to compare the demographic differences between the COPD cases and the control group, including age, gender, smoking, PIR, BMI, race, education, alcohol consumption, second-hand smoke exposure, high blood pressure, and diabetes. As the distributions of metals were right-skewed (Figure S1), the heavy metals were standardized via a natural ln (loge) transformation and the Wilcoxon rank-sum test was used to compare the metal concentration between the case group and the control group. A multiple logistic regression model was used to analyze the relationship between metals exposure and the risk of COPD. The metal exposure level was divided into tertiles (T1, T2, and T3 were the first, second, and third tertiles, respectively), T1 was used as a reference, and odds ratios (ORs) and 95\% confidence intervals (95\% CIs) were used to describe the relationship between metal exposure levels and diseases. RCS [30] was used to further analyze the relationship and trend between metal exposure and COPD because RCS not only can analyze the linear relationship between metals and the risk of COPD but also can reflect the nonlinear relationship between the two.

\section{Results}

\subsection{Demographic Characteristics}

In the study, 1399 participants were included; 107 participants with emphysema, chronic bronchitis, and COPD were classified as the COPD group; and 1292 were classified as the healthy group. There was a difference in the age distribution between the COPD group $(58.53 \pm 16.19)$ and the healthy group $(48.81 \pm 17.43)(p<0.001)$. The results showed a significant difference in smoking between the two groups $(p<0.001)$. The proportion of former smoking in the COPD group (35.45\%) was higher than that in the healthy group $(23.08 \%)$. The COPD group had higher levels of serum cotinine $(115.13 \pm 166.73)$ than the 
control group $(46.26 \pm 108.12)(p<0.001)$. Significant differences in race, BMI, education, the ratio of family income to poverty, secondhand smoke exposure, hypertension, and diabetes $(p<0.05)$ were also observed. The levels of lead, calcium, and copper in the COPD group were higher than those in the healthy group $(p<0.05)$. However, the levels of selenium in the COPD group were lower than in the healthy group $(p<0.05)$ (Table 1$)$.

Table 1. Demographic and socio-behavioral characteristics, metals level, and COPD disease status of the study population $(\mathrm{N}(\%))$.

\begin{tabular}{|c|c|c|c|}
\hline \multirow{2}{*}{ Variables } & Healthy & COPD & \multirow{2}{*}{$p$-Value } \\
\hline & $(\mathrm{N}=1292)$ & $(\mathrm{N}=107)$ & \\
\hline Age & $48.81 \pm 17.43^{\mathrm{a}}$ & $58.53 \pm 16.19^{a}$ & $<0.001^{* * *}$ \\
\hline Sex & & & 0.828 \\
\hline Male & $642(49.69)$ & $52(48.60)$ & \\
\hline Female & $650(50.31)$ & $55(51.40)$ & \\
\hline Race & & & $<0.001^{* * *}$ \\
\hline Mexican American & $233(18.03)$ & $8(7.48)$ & \\
\hline Other Hispanic & $167(12.93)$ & $20(78.69)$ & \\
\hline Non-Hispanic White & $442(34.21)$ & $60(56.07)$ & \\
\hline Non-Hispanic Black & $252(19.50)$ & $16(14.95)$ & \\
\hline Other Race & $198(15.33)$ & $3(2.80)$ & \\
\hline BMI $\left(\mathrm{kg} / \mathrm{m}^{2}\right)$ & & & 0.019 * \\
\hline$<18.5$ & $18(1.39)$ & $1(0.93)$ & \\
\hline $18.5-25$ & $325(25.15)$ & $16(14.95)$ & \\
\hline $25-30$ & $437(33.82)$ & $32(29.91)$ & \\
\hline$\geq 30$ & $512(39.63)$ & $58(54.21)$ & \\
\hline Education & & & $0.025 *$ \\
\hline Less than 9th grade & $134(10.37)$ & $17(15.89)$ & \\
\hline 9-11 grade & $142(10.99)$ & $15(14.02)$ & \\
\hline High school graduate & $293(22.68)$ & $26(24.30)$ & \\
\hline Some college/AA degree & $379(29.33)$ & $35(32.71)$ & \\
\hline College graduate & $344(26.63)$ & $14(13.08)$ & \\
\hline Ratio of Family Income to Poverty & & & $0.001 * *$ \\
\hline Under standard level & $1071(82.89)$ & $102(95.33)$ & \\
\hline Above standard level & $221(17.11)$ & $5(4.67)$ & \\
\hline Smoking & & & $<0.001^{* * *}$ \\
\hline Current smoking & $751(58.13)$ & $31(28.97)$ & \\
\hline Non-smoking & $234(18.11)$ & $38(35.51)$ & \\
\hline Former smoking & $307(23.76)$ & $38(35.51)$ & \\
\hline Secondhand smoke exposure & & & $0.013 * *$ \\
\hline Yes & $947(75.39)$ & $69(64.49)$ & \\
\hline No & $318(24.61)$ & $38(35.51)$ & \\
\hline Serum cotinine (ng/mL) & $0.03(0.01,4.08)^{b}$ & $0.18(0.01,227)^{b}$ & $<0.001^{* * *}$ \\
\hline Drinking & & & 0.052 \\
\hline Yes & $899(69.58)$ & $84(78.50)$ & \\
\hline No & $393(30.42)$ & $23(21.50)$ & \\
\hline Hypertension & & & $<0.001^{* * *}$ \\
\hline Yes & $428(33.13)$ & $67(62.62)$ & \\
\hline No & $864(66.87)$ & $40(37.38)$ & \\
\hline Diabetes & & & $<0.001 *$ \\
\hline Yes & $198(15.33)$ & $35(32.71)$ & \\
\hline No & $1094(84.67)$ & $72(67.29)$ & \\
\hline Blood $\mathrm{Pb}(\mu \mathrm{g} / \mathrm{dL})$ & $0.93(0.59,1.49)^{b}$ & $1.20(0.75,2.02)^{b}$ & $<0.001^{* * *}$ \\
\hline Tertile $1(0.05-0.71)$ & $445(34.44)$ & $23(21.50)$ & \\
\hline Tertile 2 (0.72-1.32) & $431(33.36)$ & $34(31.78)$ & \\
\hline Tertile 3 (1.33-23.51) & $416(32.20)$ & $50(46.73)$ & \\
\hline
\end{tabular}


Table 1. Cont.

\begin{tabular}{|c|c|c|c|}
\hline \multirow{2}{*}{ Variables } & Healthy & COPD & \multirow{2}{*}{$p$-Value } \\
\hline & $(\mathrm{N}=1292)$ & $(N=107)$ & \\
\hline Blood Cd ( $\mu \mathrm{g} / \mathrm{L})$ & $0.29(0.18,0.50)^{b}$ & $0.41(0.23,0.93)^{b}$ & $<0.001^{* * *}$ \\
\hline Tertile $1(0.07-0.22)$ & $458(35.45)$ & $26(24.30)$ & \\
\hline Tertile $2(0.23-0.42)$ & $426(32.97)$ & $28(26.17)$ & \\
\hline Tertile $3(0.43-6.37)$ & $408(31.58)$ & $53(49.53)$ & \\
\hline Blood Mn $(\mu \mathrm{g} / \mathrm{L})$ & $9.52(7.72,11.91)^{b}$ & $9.72(7.61,11.83)^{b}$ & 0.862 \\
\hline Tertile 1 (2.31-8.30) & $427(33.05)$ & $40(37.38)$ & \\
\hline Tertile 2 (8.31-10.96) & $439(33.98)$ & $27(25.23)$ & \\
\hline Tertile $3(10.97-56.56)$ & $426(32.97)$ & $40(37.38)$ & \\
\hline Blood Se $(\mu \mathrm{g} / \mathrm{L})$ & $192.75(178.99,207.38)^{b}$ & $189.26(176.96,201.26)^{b}$ & 0.070 \\
\hline Tertile 1 (119.87-183.22) & $427(33.05)$ & $40(37.38)$ & \\
\hline Tertile 2 (183.23-201.75) & $423(32.74)$ & $43(40.19)$ & \\
\hline Tertile 3 (201.76-318.33) & $442(34.21)$ & $24(22.43)$ & \\
\hline Serum $\mathrm{Cu}(\mu \mathrm{g} / \mathrm{dL})$ & $114.25(99.15,133.10)^{b}$ & $124.30(110.40,145.00)^{b}$ & $<0.001^{* * *}$ \\
\hline Tertile 1 (52.90-105.00) & $454(35.14)$ & $18(16.82)$ & \\
\hline Tertile 2 (105.01-126.60) & $425(32.89)$ & $38(35.51)$ & \\
\hline Tertile 3 (126.61-306.60) & $413(31.97)$ & $51(47.66)$ & \\
\hline Serum $\mathrm{Zn}(\mu \mathrm{g} / \mathrm{dL})$ & $79.90(69.80,89.90)^{b}$ & $80.90(72.50,91.10)^{b}$ & 0.408 \\
\hline Tertile $1(31.40-73.70)$ & $442(34.21)$ & $27(25.23)$ & \\
\hline Tertile 2 (73.71-86.40) & $416(32.20)$ & $48(44.86)$ & \\
\hline Tertile 3 (86.41-139.10) & $434(33.59)$ & $32(29.91)$ & \\
\hline
\end{tabular}

Note: ${ }^{*}, p<0.05 ;{ }^{* *}, p<0.01 ; * * *, p<0.001$. a The continuous variables were represented by mean \pm SD. $b$ Non-normally distributed continuous variables were represented by IQR: P50(P25, P75).

\subsection{The Association between Metals, Trace Mineral Exposure, and the Risk of COPD}

The second and third tertiles of copper increased the risk of COPD by 2.02 times and 2.50 times compared with the first tertile after adjusting for other covariates, respectively, the $p$-value for trend was 0.005 (T2 95\% CI: 1.10-3.73; T3 95\% CI: 1.34-4.65) (Figure 2). We further analyzed their relationships stratified by gender. The third tertile of copper only increased COPD risk in males by 3.31 times ( $p=0.004,95 \%$ CI: $1.47-7.44)$ compared with the lowest tertile, and the $p$-value for trend was 0.004 (Table 2).

\subsection{Dose-Response Relationship between Metals and the Risk of COPD}

RCS showed that there was a linear relationship between $\ln$ (copper)- exposure and the risk of COPD ( $p=0.006$ for overall association) in all participants. As the $\ln$ (copper) level increased, the risk of COPD increased (Figure 3A). Both $\ln$ (copper) $(p=0.013$ for overall association) and $\ln$ (selenium) ( $p=0.008$ for overall association) had linear relationships with the risk of COPD in males. As the $\ln$ (copper) level increased, the risk of COPD increased (Figure 3C); however, as the level of $\ln$ (selenium) increased, the risk of COPD decreased in males (Figure 3D). We did not observe this relationship in females (Figure 3E,F). 


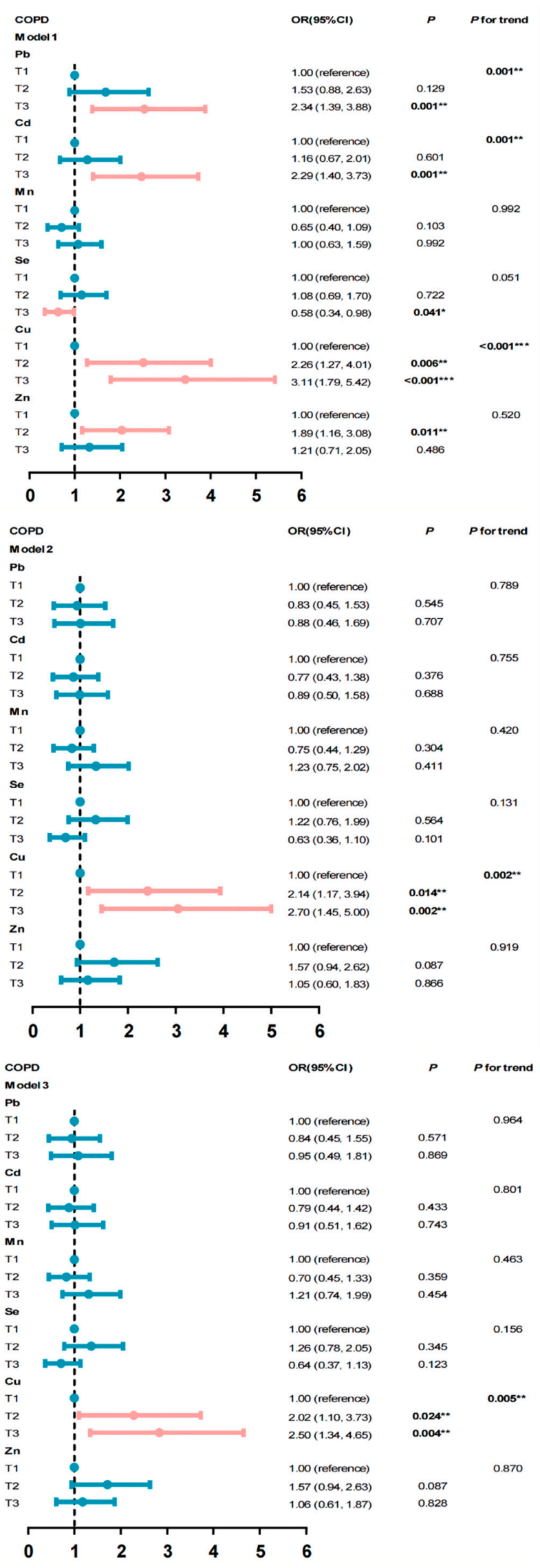

Figure 2. Association between COPD and metals. Model 1: unadjusted model; Model 2: adjusted for age, smoke, ratio of family income to poverty, BMI, sex, race, education, drink, second-hand smoke 
exposure, and serum cotinine; Model 3: adjusted for age, smoke, ratio of family income to poverty, BMI, sex, race education, drink, second-hand smoke exposure, serum cotinine, hypertension, and diabetes. ${ }^{*} p<0.05 ;{ }^{* *} p<0.01$; and ${ }^{* * *} p<0.001$.

\section{A}

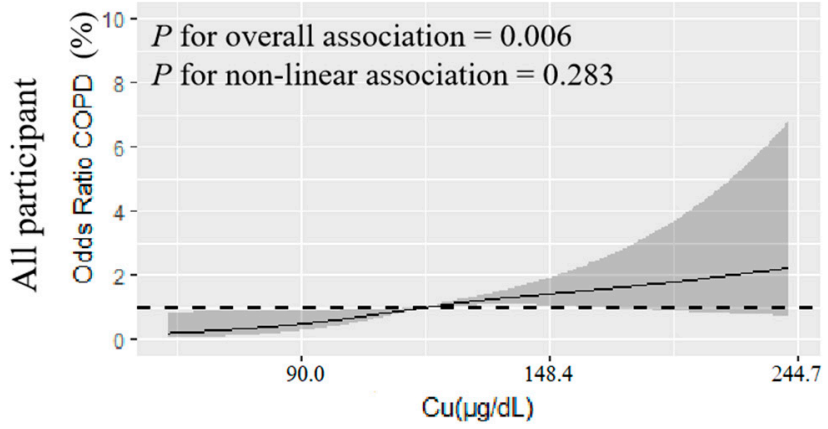

C

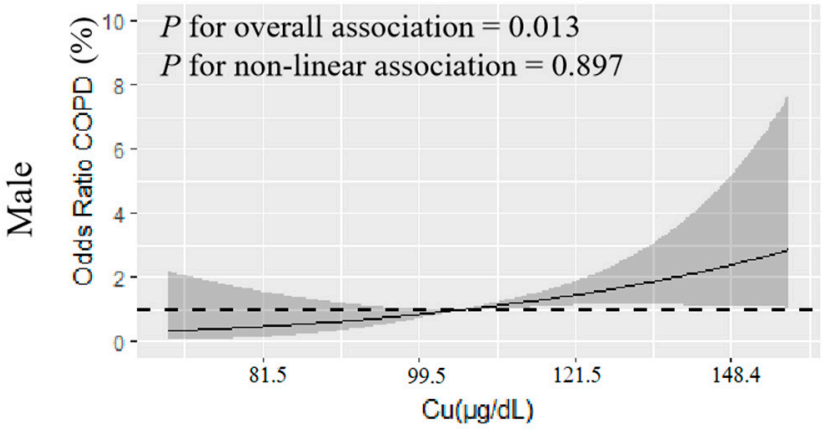

E

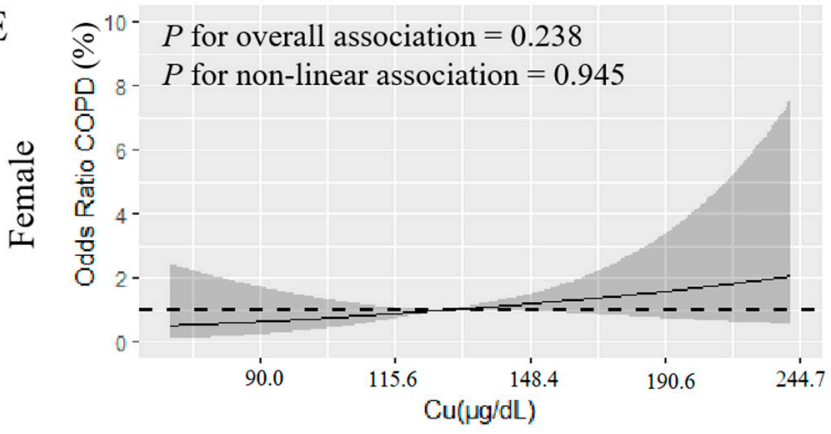

$\mathrm{B}$

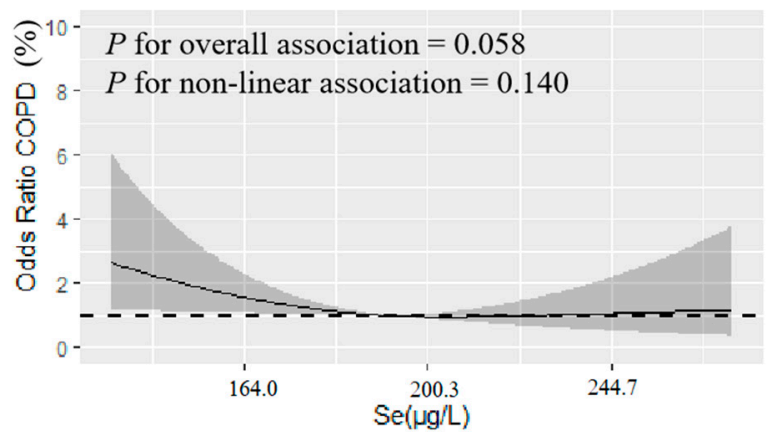

$\mathrm{D}$

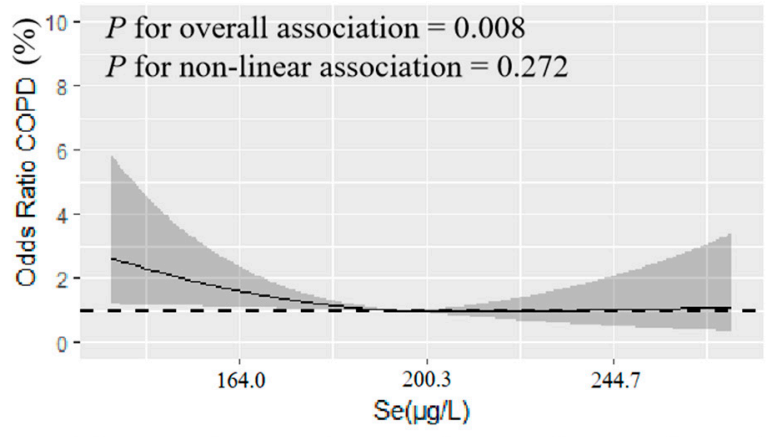

F

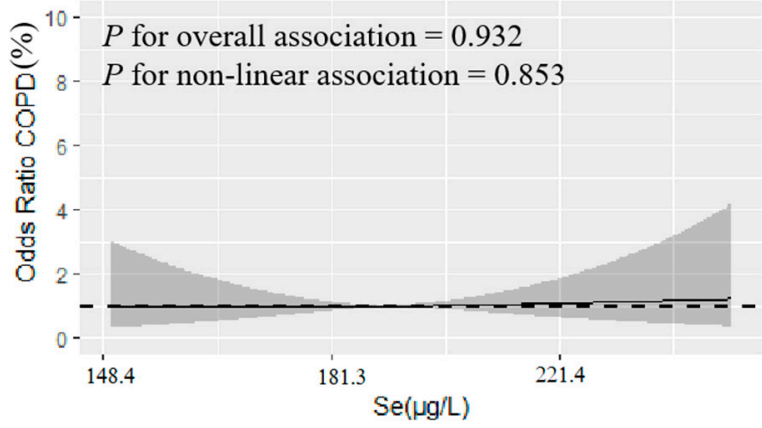

Figure 3. (A-F) used restricted cubic spline modeling to analyze the relationship between metals, trace minerals, and COPD (ln-transformed). $(\mathbf{A}, \mathbf{B})$ is the relationship between copper, selenium, and COPD in all survey subjects, (C,D) is the relationship between copper, selenium, and COPD in males, and $(\mathbf{E}, \mathbf{F})$ is the relationship between copper, selenium, and COPD in females. The analysis adjusted for age, smoke, ratio of family income to poverty, BMI, sex, race education, drink, second-hand smoke exposure, serum cotinine, hypertension, and diabetes. The black solid line represents the combined restricted cubic spline curve model, and the shaded part represents the $95 \% \mathrm{CI}$ of the combined curve. 
Table 2. Risk of COPD associated with level of metals in different genders.

\begin{tabular}{|c|c|c|c|c|c|c|}
\hline \multirow{2}{*}{ variables } & \multicolumn{3}{|c|}{ Male } & \multicolumn{3}{|c|}{ Female } \\
\hline & OR & $p$ & $95 \%$ CI & OR & $p$ & $95 \%$ CI \\
\hline \multicolumn{7}{|l|}{$\mathrm{Pb}$} \\
\hline $\mathrm{T} 1$ & 1.00 & 1.00 & 1.00 & 1.00 & 1.00 & 1.00 \\
\hline $\mathrm{T} 2$ & 1.20 & 0.752 & $0.38-3.79$ & 0.78 & 0.522 & $0.36-1.68$ \\
\hline T3 & 1.70 & 0.362 & $0.54-5.31$ & 0.68 & 0.384 & $0.28-1.63$ \\
\hline$p$ for trend & & 0.279 & & & 0.388 & \\
\hline \multicolumn{7}{|l|}{$\mathrm{Cd}$} \\
\hline $\mathrm{T} 1$ & 1.00 & 1.00 & 1.00 & 1.00 & 1.00 & 1.00 \\
\hline $\mathrm{T} 2$ & 0.65 & 0.378 & $0.26-1.68$ & 0.80 & 0.576 & $0.37-1.74$ \\
\hline $\mathrm{T} 3$ & 1.64 & 0.235 & $0.73-3.69$ & 0.48 & 0.110 & $0.19-1.18$ \\
\hline$p$ for trend & & 0.160 & & & 0.109 & \\
\hline \multicolumn{7}{|l|}{$\mathrm{Mn}$} \\
\hline $\mathrm{T} 1$ & 1.00 & 1.00 & 1.00 & 1.00 & 1.00 & 1.00 \\
\hline $\mathrm{T} 2$ & 0.90 & 0.796 & 0.41-1.99 & 0.66 & 0.278 & $0.31-1.40$ \\
\hline T3 & 1.74 & 0.122 & $0.86-3.50$ & 0.85 & 0.654 & $0.41-1.74$ \\
\hline$p$ for trend & & 0.147 & & & 0.696 & \\
\hline \multicolumn{7}{|l|}{ Se } \\
\hline $\mathrm{T} 1$ & 1.00 & 1.00 & 1.00 & 1.00 & 1.00 & 1.00 \\
\hline $\mathrm{T} 2$ & 0.86 & 0.683 & $0.43-1.75$ & 1.79 & 0.092 & $0.91-3.53$ \\
\hline T3 & 0.48 & 0.078 & $0.22-1.08$ & 0.83 & 0.633 & $0.38-1.81$ \\
\hline$p$ for trend & & 0.081 & & & 0.806 & \\
\hline \multicolumn{7}{|l|}{$\mathrm{Cu}$} \\
\hline $\mathrm{T} 1$ & 1.00 & 1.00 & 1.00 & 1.00 & 1.00 & 1.00 \\
\hline $\mathrm{T} 2$ & 1.65 & 0.200 & $0.77-3.52$ & 2.53 & 0.113 & $0.80-7.96$ \\
\hline T3 & 3.31 & $0.004^{* *}$ & $1.47-7.44$ & 2.38 & 0.128 & $0.78-7.28$ \\
\hline$p$ for trend & & $0.004^{* *}$ & & & 0.247 & \\
\hline \multicolumn{7}{|l|}{$\mathrm{Zn}$} \\
\hline $\mathrm{T} 1$ & 1.00 & 1.00 & 1.00 & 1.00 & 1.00 & 1.00 \\
\hline $\mathrm{T} 2$ & 1.43 & 0.332 & $0.69-2.96$ & 1.81 & 0.124 & $0.85-3.86$ \\
\hline $\mathrm{T} 3$ & 0.72 & 0.423 & $0.32-1.62$ & 1.70 & 0.195 & $0.76-3.80$ \\
\hline$p$ for trend & & 0.420 & & & 0.212 & \\
\hline
\end{tabular}

Note: ${ }^{* *} p<0.01$. The models were adjusted for age, smoke, ratio of family income to poverty, BMI, sex, race education, drink, second-hand smoke exposure, serum cotinine, hypertension, and diabetes.

\section{Discussion}

In our research, the high concentration of copper was positively correlated with COPD in males in the general US population using a multiple linear regression and restricted cubic spline modeling. While the risk of a male suffering from COPD decreased with the increase in selenium concentration ( $p=0.008$ for overall association). Studies have shown that copper is an important cofactor for some enzymatic reactions $[9,31]$, and its mechanism may be related to Lysyl oxidase-like 2 (LOXL 2) [31-33]. LOXL 2 is a copper-dependent amine oxidase, which can activate lung fibroblasts through the TGF- $\beta$ /Smad pathway, leading to pulmonary fibrosis, which in turn leads to impaired lung function. Selenium is related to the cellular antioxidant defense mechanism. Oxidative stress and chronic inflammation are important features in the pathogenesis of COPD [21]. Selenium is a cofactor of glutathione peroxidase, which can protect the human body from cell membrane damage mediated by reactive oxygen species and free radicals [34-37].

Selenium, cadmium, and lead are enriched in lung tissue [38], but copper, manganese, and zinc have not been reported. A study has shown that the median concentrations of lead, copper, manganese, selenium, copper, and zinc in the lung were $0.072,0.026,0.058$, $0.11,1.10$, and $10.7 \mu \mathrm{g} / \mathrm{g}$ wet weight (ppm), respectively, among eight individuals in the age range 43 to 72 years [38]. The biological half-life of copper from the diet is 13-33 days, with bilary excretion being the major route of elimination [39]. Experiments of inhaled selenious acid and selenium metal aerosols in beagle dogs showed that the long-term component of the whole-body retention function for both inhaled aerosols had a half-life of about 34 days 
and accounted for about $20 \%$ of the initial selenium dose, and urine was the major route of excretion, accounting for 70 to $80 \%$ of the excreted selenium [40]. Therefore, one-time measures in serum of copper and blood of selenium are reflective of recent exposures.

The recommended intake of copper is $900 \mu \mathrm{g} /$ day according to the Food and Nutrition Board (FNB) of the Institute of Medicine of the National Academy of Sciences [41]. The main dietary sources of copper are shellfish, seeds, nuts, offal, wheat bran cereals, whole grain products, and chocolate [41,42]. Although in our study, the concentration of the copper in the COPD group $(124.30 \mu \mathrm{g} / \mathrm{dL})$ was higher than the healthy group $(114.25 \mu \mathrm{g} / \mathrm{dL})$, they did not exceed the normal range (63.5-158.9 $\mu \mathrm{g} / \mathrm{dL})$ [43]. This is consistent with the results of Cen Jiang et al. [44]. Pearson's research showed that copper had a strong negative correlation with lung function, and the higher serum copper levels reduce the forced expiratory volume in $1 \mathrm{~s}$ [45].

We found that copper only increased the risk of COPD in males, not females, but the serum copper in females $(126.60 \mu \mathrm{g} / \mathrm{dL})$ was higher than that in males $(105.10 \mu \mathrm{g} / \mathrm{dL})$ $(p<0.001)$ (Table S1). It might be the difference in sex hormones between males and females. Copper can activate lung fibroblasts through LOXL 2 activation of the TGF- $\beta$ /Smad pathway, leading to pulmonary fibrosis, which in turn causes COPD [31-33]. Estrogen can inhibit the proliferation of fibroblasts through the Raf1-ERK-MAPK pathway [46,47]. The protective effect of estrogen might explain the sex-specific difference to copper. Therefore, based on our study, we suggest that the standard for serum copper concentration should be lowed and established according to gender.

The selenium intake of Americans exceeds $100 \mu \mathrm{g} / \mathrm{d}$, which is much higher than the recommended intake $(55 \mu \mathrm{g} / \mathrm{d})$ [48] because of the high concentration of selenium in the soil. In addition, 18-19\% of adults and children also use dietary supplements containing selenium [49]. The levels of selenium in the healthy group $(192.75 \mu \mathrm{g} / \mathrm{L})$ and COPD group $(189.26 \mu \mathrm{g} / \mathrm{L})$ were higher than normal concentrations $(136.7 \mu \mathrm{g} / \mathrm{L})$ [48]. Selenium is a cofactor of glutathione peroxidase, which can protect the human body from cell membrane damage mediated by reactive oxygen species and free radicals [34-37]. Wei Feng et al. [50] found that $\ln$ (selenium) has a positive linear relationship with the increase in lung function, but the COPD risk was not covered in the study. An RCT proved that selenium combined with vitamin $C$ can alleviate the deterioration of COPD [51]. Our results also showed that selenium can reduce the risk of COPD.

There are some limitations to our study. First, because it was a cross-sectional study, the evidence for causality was not strong. Second, the data came from the NHANES, and it cannot represent the whole situation in the world and it needs to be verified in other populations. Third, there is no professional diagnosis of COPD by a doctor in NHANES. Although the definition of COPD depended on the participants' answer to "Has a doctor told you have COPD, emphysema and chronic bronchitis?", which is consistent with the previous studies about COPD using NHANES data, it might cause some bias in our studies.

In the 2015-2016 NHANES data, only copper and selenium exposure were related to the COPD in US male population. It is necessary to conduct in-depth research to verify this result and to investigate its potential mechanism. More research is expected to explore the relationship between metals and COPD, and the standard for serum copper concentration should establish by gender.

\section{Conclusions}

In our research, the high concentration of copper increased the COPD risk in males in the general US population using the multiple linear regression and restricted cubic spline modeling. While the risk of male suffering from COPD decreased with the increasing selenium level, we did not find associations between copper, selenium and the risk of COPD in female. We hope that there will be more research exploring the relationship between metals and COPD, and based on our study, we hope that the standard for serum copper concentration should be lowed and established according to gender. 
Supplementary Materials: The following supporting information can be downloaded at: https: / / www.mdpi.com/article/10.3390/ijerph19042085/s1. Figure S1: Distribution of exposure variables, Table S1: Level of metals in male and female.

Author Contributions: Q.F., X.W. and K.L.: Conceptualization, Writing—original draft, and Writingreview and editing. S.L.: Data curation and Resources. J.C.: Investigation and Resources. X.G.: Software and Validation. C.J.: Validation, Supervision, Writing-review and editing, and Project administration. All authors have read and agreed to the published version of the manuscript.

Funding: This research did not receive any specific funding from any funding agency.

Institutional Review Board Statement: The NHANES agreement has been reviewed and approved by the NCHS Research Ethics Committee. (approval code: Protocol \#2011-17, approval date: 26 October 2017).

Informed Consent Statement: All participants provided written informed consent.

Data Availability Statement: All data in the article can be downloaded for free in the NHANES database from https:/ / www.cdc.gov/nchs/nhanes/ (accessed on 1 May 2021).

Acknowledgments: Thanks to the data provided by the National Health and Nutrition Examination Survey (2015-2016) of the United States, which are used in epidemiological research and health science research to help formulate sound public health policies, to guide and design health plans and services, and to expand health knowledge.

Conflicts of Interest: The authors declare no conflict of interest.

\section{References}

1. Ibrahimou, B.; Azim, S.I.; Sun, N. Interaction between blood lead level and chronic obstructive pulmonary disease (COPD) on risk of heart attack or stroke: USA NHANES, 2013-2014. Pulm. Pharmacol. Ther. 2019, 58, 101805. [CrossRef]

2. Vogelmeier, C.F.; Criner, G.J.; Martinez, F.J.; Anzueto, A.; Barnes, P.J.; Bourbeau, J.; Celli, B.R.; Chen, R.; Decramer, M.; Fabbri, L.M.; et al. Global strategy for the diagnosis, management, and prevention of chronic obstructive lung disease 2017 report. GOLD executive summary. Am. J. Respir. Crit. Care Med. 2017, 195, 557-582. [CrossRef]

3. Global Status of COPD. Available online: https://www.who.int/respiratory/copd/burden/zh/ (accessed on 2 October 2021).

4. López-Campos, J.L.; Tan, W.; Soriano, J.B. Global burden of COPD. Respirology 2016, 21, 14-23. [CrossRef]

5. Vos, T.; Lim, S.S.; Abbafati, C.; Abbas, K.M.; Abbasi, M.; Abbasifard, M.; Abbasi-Kangevari, M.; Abbastabar, H.; Abd-Allah, F.; Abdelalim, A.; et al. Global burden of 369 diseases and injuries in 204 countries and territories, 1990-2019: A systematic analysis for the Global Burden of Disease Study 2019. Lancet 2020, 396, 1204-1222. [CrossRef]

6. Fernandes, L.; Mesquita, A. Biomass smoke exposure is the main risk factor for COPD in non smoking women in a developing country. Eur. Respir. J. 2013, 42, 2008.

7. Matheson, M.C.; Benke, G.; Raven, J.; Sim, M.R.; Kromhout, H.; Vermeulen, R.; Johns, D.P.; Walters, E.H.; Abramson, M.J. Biological dust exposure in the workplace is a risk factor for chronic obstructive pulmonary disease. Thorax 2005, 60, 645-651. [CrossRef]

8. De Marco, R.; Accordini, S.; Marcon, A.; Cerveri, I.; Antó, J.M.; Gislason, T.; Heinrich, J.; Janson, C.; Jarvis, D.; Kuenzli, N.; et al. Risk factors for chronic obstructive pulmonary disease in a European cohort of young adults. Am. J. Respir. Crit. Care Med. 2011, 183, 891-897. [CrossRef]

9. Sparrow, D.; Silbert, J.E.; Weiss, S.T. The relationship of pulmonary function to copper concentrations in drinking water. Am. Rev. Respir. Dis. 1982, 126, 312-315.

10. Xiao, L.; Zhou, Y.; Cui, X.; Huang, X.; Yuan, J.; Chen, W. Association of urinary metals and lung function in general Chinese population of Wuhan. Zhonghua Yu Fang Yi Xue Za Zhi 2016, 50, 680-688.

11. Pappas, R.S.; Fresquez, M.R.; Martone, N.; Watson, C.H. Toxic metal concentrations in mainstream smoke from cigarettes available in the USA. J. Anal. Toxicol. 2014, 38, 204-211. [CrossRef]

12. Piadé, J.J.; Jaccard, G.; Dolka, C.; Belushkin, M.; Wajrock, S. Differences in cadmium transfer from tobacco to cigarette smoke, compared to arsenic or lead. Toxicol. Rep. 2015, 2, 12-26. [CrossRef]

13. Richter, P.; Faroon, O.; Pappas, R.S. Cadmium and cadmium/zinc ratios and tobacco-related morbidities. Int. J. Environ. Res. Public Health 2017, 14, 1154. [CrossRef]

14. Manca, D.; Ricard, A.C.; Trottier, B.; Chevalier, G. Studies on lipid peroxidation in rat tissues following administration of low and moderate doses of cadmium chloride. Toxicology 1991, 67, 303-323. [CrossRef]

15. Faroon, O.; Ashizawa, A.; Wright, S.; Tucker, P.; Jenkins, K.; Ingerman, L.; Rudisill, C. Agency for Toxic Substances and Disease Registry (ATSDR) Toxicological Profiles. In Toxicological Profile for Cadmium; Agency for Toxic Substances and Disease Registry (US): Atlanta, GA, USA, 2012. 
16. Anetor, J.; Ajose, F.; Anetor, G.; Iyanda, A.; Babalola, B.; Adeniyi, F. High cadmium/zinc ratio in cigarette smokers: Potential implications as a biomarker of risk of prostate cancer. Niger. J. Physiol. Sci. 2008, 23, 41-49. [CrossRef]

17. Ibs, K.H.; Rink, L. Zinc-altered immune function. J. Nutr. 2003, 133, 1452S-1456S. [CrossRef]

18. Rink, L.; Kirchner, H. Zinc-altered immune function and cytokine production. J. Nutr. 2000, 130, 1407S-1411S. [CrossRef]

19. Meydani, S.N.; Barnett, J.B.; Dallal, G.E.; Fine, B.C.; Jacques, P.F.; Leka, L.S.; Hamer, D.H. Serum zinc and pneumonia in nursing home elderly. Am. J. Clin. Nutr. 2007, 86, 1167-1173. [CrossRef]

20. Lin, Y.S.; Caffrey, J.L.; Chang, M.H.; Dowling, N.; Lin, J.W. Cigarette smoking, cadmium exposure, and zinc intake on obstructive lung disorder. Respir. Res. 2010, 11, 53. [CrossRef]

21. Rahman, I.; Kilty, I. Antioxidant therapeutic targets in COPD. Curr. Drug Targets 2006, 7, 707-720. [CrossRef]

22. Hassan, F.; Xu, X.; Nuovo, G.; Killilea, D.W.; Tyrrell, J.; Da Tan, C.; Tarran, R.; Diaz, P.; Jee, J.; Knoell, D.; et al. Accumulation of metals in GOLD4 COPD lungs is associated with decreased CFTR levels. Respir. Res. 2014, 15, 69. [CrossRef]

23. Rokadia, H.K.; Agarwal, S. Serum heavy metals and obstructive lung disease: Results from the National Health and Nutrition Examination Survey. Chest 2013, 143, 388-397. [CrossRef]

24. Thomas, R. Practical Guide to ICP-MS: A Tutorial for Beginners; CRC Press: Boca Raton, FL, USA, 2008.

25. Tanner, S.D.; Baranov, V.I. Theory, design, and operation of a dynamic reaction cell for ICP-MS. At. Spectrosc. Norwalk Conn. 1999, $20,45-52$.

26. Tanner, S.D.; Baranov, V.I.; Bandura, D.R. Reaction cells and collision cells for ICP-MS: A tutorial review. Spectrochim. Acta Part B At. Spectrosc. 2002, 57, 1361-1452. [CrossRef]

27. Navaneethan, S.D.; Mandayam, S.; Arrigain, S.; Rahman, M.; Winkelmayer, W.C.; Schold, J.D. Obstructive and restrictive lung function measures and CKD: National Health and nutrition examination survey (NHANES) 2007-2012. Am. J. Kidney Dis. 2016, 68, 414-421. [CrossRef]

28. Dong, X.; Li, S.; Sun, J.; Zhang, D. Association of Coffee, Decaffeinated Coffee and Caffeine Intake from Coffee with Cognitive Performance in Older Adults: National Health and Nutrition Examination Survey (NHANES) 2011-2014. Nutrients 2020, 12, 840. [CrossRef]

29. Madrigal, J.M.; Persky, V.; Pappalardo, A.; Argos, M. Association of heavy metals with measures of pulmonary function in children and youth: Results from the National Health and Nutrition Examination Survey (NHANES). Environ. Int. 2018, 121, 871-878. [CrossRef]

30. Desquilbet, L.; Mariotti, F. Dose-response analyses using restricted cubic spline functions in public health research. Stat. Med. 2010, 29, 1037-1057. [CrossRef]

31. Wen, X.; Liu, Y.; Bai, Y.; Li, M.; Fu, Q.; Zheng, Y. LOXL2, a copper-dependent monoamine oxidase, activates lung fibroblasts through the TGF- $\beta /$ Smad pathway. Int. J. Mol. Med. 2018, 42, 3530-3541. [CrossRef]

32. Baldari, S.; Di Rocco, G.; Toietta, G. Current biomedical use of copper chelation therapy. Int. J. Mol. Sci. 2020, 21, 1069. [CrossRef]

33. Janssen, R.; de Brouwer, B.; Jan, H.; Wouters, E.F. Copper as the most likely pathogenic divergence factor between lung fibrosis and emphysema. Med. Hypotheses 2018, 120, 49-54. [CrossRef]

34. Bastola, M.M.; Locatis, C.; Maisiak, R.; Fontelo, P. Selenium, copper, zinc and hypertension: An analysis of the National Health and Nutrition Examination Survey (2011-2016). BMC Cardiovasc. Disord. 2020, 20, 45. [CrossRef]

35. Suadicani, P.; Hein, H.O.; Gyntelberg, F. Serum selenium level and risk of lung cancer mortality: A 16-year follow-up of the Copenhagen Male Study. Eur. Respir. J. 2012, 39, 1443-1448. [CrossRef]

36. Salmonowicz, B.; Krzystek-Korpacka, M.; Noczynska, A. Trace elements, magnesium, and the efficacy of antioxidant systems in children with type 1 diabetes mellitus and in their siblings. Adv. Clin. Exp. Med. 2014, 23, 259-268. [CrossRef]

37. Alkan, F.A.; Karis, D.; Cakmak, G.; Ercan, A.M. Analysis of the relationship between hemorheologic parameters, aluminum, manganese, and selenium in smokers. Biol. Trace Elem. Res. 2019, 187, 22-31. [CrossRef]

38. Brune, D.; Nordberg, G.; Wester, P.O. Distribution of 23 elements in the kidney, liver and lungs of workers from a smeltery and refinery in North Sweden exposed to a number of elements and of a control group. Sci. Total Environ. 1980, 16, 13-35. [CrossRef]

39. Barceloux, D.G.; Barceloux, D. Copper. J. Toxicol. Clin. Toxicol. 1999, 37, 217-230. [CrossRef]

40. Weissman, S.H.; Cuddihy, R.G.; Medinsky, M.A. Absorption, distribution, and retention of inhaled selenious acid and selenium metal aerosols in beagle dogs. Toxicol. Appl. Pharmacol. 1983, 67, 331-337. [CrossRef]

41. Li, S.; Sun, W.; Zhang, D. Association of zinc, iron, copper, and selenium intakes with low cognitive performance in older adults: A cross-sectional study from National Health and Nutrition Examination Survey (NHANES). J. Alzheimer's Dis. 2019, 72, 1145-1157. [CrossRef]

42. Kies, C. Food sources of dietary copper. Copper bioavailability and metabolism. Adv. Exp. Med. Biol. 1989, 258, 1-20.

43. U.S. Copper Intake. Available online: https://ods.od.nih.gov/factsheets/Copper-HealthProfessional/ (accessed on 2 October 2021).

44. Jiang, C.; Wu, B.; Xue, M.; Lin, J.; Hu, Z.; Nie, X.; Cai, G. Inflammation accelerates copper-mediated cytotoxicity through induction of six-transmembrane epithelial antigens of prostate 4 expression. Immunol. Cell Biol. 2021, 99, 392-402. [CrossRef]

45. Pearson, P.; Britton, J.; McKeever, T.; Lewis, S.; Weiss, S.; Pavord, I.; Fogarty, A. Lung function and blood levels of copper, selenium, vitamin C and vitamin E in the general population. Eur. J. Clin. Nutr. 2005, 59, 1043-1048. [CrossRef]

46. Tofovic, S.P.; Zhang, X.; Jackson, E.K.; Zhu, H.; Petrusevska, G. 2-methoxyestradiol attenuates bleomycin-induced pulmonary hypertension and fibrosis in estrogen-deficient rats. Vasc. Pharmacol. 2009, 51, 190-197. [CrossRef] 
47. Sathish, V.; Martin, Y.N.; Prakash, Y. Sex steroid signaling: Implications for lung diseases. Pharmacol. Ther. 2015, 150, 94-108. [CrossRef]

48. U.S. Selenium Intake. Available online: https://ods.od.nih.gov/factsheets/Selenium-HealthProfessional/ (accessed on 2 October 2021).

49. Bailey, R.L.; Gahche, J.J.; Lentino, C.V.; Dwyer, J.T.; Engel, J.S.; Thomas, P.R.; Betz, J.M.; Sempos, C.T.; Picciano, M.F. Dietary supplement use in the United States, 2003-2006. J. Nutr. 2011, 141, 261-266. [CrossRef]

50. Feng, W.; Huang, X.; Zhang, C.; Liu, C.; Cui, X.; Zhou, Y.; Sun, H.; Qiu, G.; Guo, H.; He, M.; et al. The dose-response association of urinary metals with altered pulmonary function and risks of restrictive and obstructive lung diseases: A population-based study in China. BMJ Open 2015, 5, e007643. [CrossRef]

51. Isbaniah, F.; Wiyono, W.H.; Yunus, F.; Setiawati, A.; Totzke, U.; Verbruggen, M. Echinacea purpurea along with zinc, selenium and vitamin $\mathrm{C}$ to alleviate exacerbations of chronic obstructive pulmonary disease: Results from a randomized controlled trial. $J$. Clin. Pharm. Ther. 2011, 36, 568-576. [CrossRef] 